\title{
NAS TRILHAS DE EÇA E SARAMAGO: REPRESENTAÇÕES DE CRISTO NO SÉCULO XX
}

Aparecida de Fátima Bueno

Universidade de São Paulo

A religião cristã faz parte do património que Portugal herdou do passado quando se constituiu nação independente (século XII).

Joel Serrão

A

ntónio Machado Pires, no longo ensaio em que analisa a idéia da decadência na geração de 70, aponta para o fato de essa geração ter posto em discussão, sob vários ângulos, a identidade nacional portuguesa (PIRES, 1992, p.53). Sem dúvida um desses ângulos é a complexa relação com o religioso, existente no país desde a fundação da nacionalidade, haja vista a força e permanência da imagem de Portugal como povo eleito por Deus, predestinado a dilatar a fé e o império, imagem esta que o propagado "milagre" de Ourique ajudou a corroborar.

Entre as estratégias utilizadas pela geração de 70 em seu questionamento da sociedade de seu país estava a crítica à atuação e ao comportamento do clero, sobretudo na sociedade portuguesa oitocentista. Movida pelo forte sentimento anticlerical, então bastante revigorado, atenta às várias exegeses bíblicas que vieram a lume na Alemanha e França, essa geração, acompanhando de perto o movimento europeu, vai além da crítica anticlerical, pois culmina por colocar em xeque a divindade de Jesus.

$A$ relíquia (1887), de Eça de Queirós é, certamente, a principal obra que marca esse movimento de releitura heterodoxa da vida de Cristo, movimento de larga tradição na literatura portuguesa, e que tem como último representante, até o momento, O Evangelho segundo Jesus Cristo (1991). Imbuídos do mesmo espírito heterodoxo que marca a obra eciana, Gomes Leal e Guerra Junqueiro, companheiros de geração, também tiveram Jesus como persona- 
gem, em diversos momentos de suas carreiras literárias ${ }^{1}$. Pretendemos, neste ensaio, fazer um levantamento da obra dos vários autores que, na trilha da geração de 70, revisitaram a vida de Jesus, ou parte da legenda bíblica, em obras de maior ou menor vulto, em que é evidente a herança deixada por seus antecessores do século XIX. Nessa perspectiva, destacam-se os nomes de António Patrício, Teixeira de Pascoaes, Raul Brandão, Fernando Pessoa, Aquilino Ribeiro, José Saramago.

António Patrício (1878-1930), na breve peça Judas, põe em cena como personagem “A Sombra de Jesus”, que aparece diante do traidor no momento em que este está para se enforcar. No belíssimo diálogo que então travam, "A Sombra de Jesus" vem resgatar Judas da ignomínia em que ele foi colocado pela tradição. Declara que "Dos Doze és para mim o mais amado”. Diante do arrependimento e angústia de Judas pelo feito cometido, "A sombra de Jesus" compara o martírio do traidor com a sua própria agonia na cruz, já que "ecoou na tua carne o meu suplício”. Indaga também qual seria o seu destino se não houvesse o ato de traição: "E que fora, sem ti, o meu destino? Como iriam cumprir-se as Escrituras?". Acaba, por fim, por negar a própria traição: "Não me traíste, não: serviste o Pai: e ninguém mais humildemente como tu. A tua baixeza é a tua altura" (PATRÍCIO, 1982, p.431-435 passim).

Apesar da brevidade do texto de António Patrício, essa sua interpretação da legenda bíblica, contrária a da tradição, por certo é bastante heterodoxa. A peça tem como epígrafe um trecho do capítulo XIII do Evangelho segundo João, em que Jesus aparece falando do traidor. Como sabemos, o putativo autor do quarto evangelho, o apóstolo João, em vários momentos de sua narrativa, apresenta-se como o discípulo predileto de Jesus. Ironicamente, Patrício põe na fala da "Sombra de Jesus" a declaração de que Judas é, entre os doze, o discípulo mais amado, desautorizando, portanto, o quarto evangelista.

Podemos pensar que a leitura de Patrício, que eleva Judas, contraria toda uma tradição que se formou a partir das narrativas evangélicas, que condena a uma expiação inexorável um personagem que foi execrado e,

\footnotetext{
Além de A velhice do padre eterno, Guerra Junqueiro deixou duas obras póstumas que têm Jesus como personagem: O caminho do céu (1925) e o poema inconcluso Prometeu libertado (1926). Já Gomes Leal revisita a figura de Cristo em A história de Jesus para as criancinhas lerem (1883) e O Anti-Cristo (1886).
} 
dentro de uma certa tradição popular, tem sido enxovalhado e queimado ano a ano nos sábados de Aleluia. O seu Jesus, porém, não contradiz, de certa forma, o dos Evangelhos, que tinha, como sabemos, o perdão ao próximo como um dos pontos basilares de sua pregação.

Raul Brandão e Teixeira de Pascoaes, por sua vez, na peça teatral Jesus Cristo em Lisboa, tragicomédia em sete quadros, publicada em 1930, trarão Jesus de volta a Portugal, num período contemporâneo ao que a peça veio a lume. Em muitos aspectos esse texto se parece com o poema de Guerra Junqueiro, "Semana Santa", de $A$ velhice do padre eterno (1885). Em ambos, Jesus Cristo deambula por uma cidade; na peça essa cidade é explicitamente Lisboa, como vem indicado no título, só que, ao contrário do poema, em que Jesus se mantém anônimo para preservar a sua integridade física, como o aconselha Voltaire, que o acompanha em sua deambulação, no texto de Brandão e Pascoaes, Jesus revela-se para muitos dos circunstantes que encontra em seu caminho, causando uma série de distúrbios que o levarão novamente para o suplício na cruz. Assim como no poema de Junqueiro, no texto teatral Jesus fica perplexo e escandalizado com o estado corrompido do mundo. Contracenando com uma gama variada de personagens e circulando por muitos lugares (Comissariado de Polícia, Conselho de Estado, Catedral, Habitações de gente pobre), que, como define com exatidão José Manuel de Vasconcelos, funcionam "como marcos da sua viagem pelas diversas classes e estratos sociais: os políticos, o Clero, o Povo", "Cristo atravessa a cidade de desilusão em desilusóo, é preso, ameaçado, aliciado, declarado um inimigo público e finalmente crucificado" (VASCONCELOS, 1984, p.13).

O Jesus personagem da peça comporta-se, de modo geral, da maneira como foi fixado pela tradição bíblica. Porém, é na reação negativa e na contestação dos outros personagens à sua palavra que podemos verificar um rebaixamento desse Cristo. A maioria se revolta com o estado do mundo em que vivem e acusam Jesus de desconhecer esse estado; também não compreendem a imperfeição de um mundo que foi criado por um Deus: "Porque nos deste a dor e a morte? Se tu és Deus e o mundo é a tua obra, porque o fizeste tão imperfeito?" (BRANDÃO, PASCOAES, 1984, p.100). O Anarquista, um dos personagens dessa tragicomédia, acusa Jesus Cristo de, com sua mensagem, só conseguir que os pobres se submetam aos ricos. E, mais que isto, indaga: "Mas se tu és Deus, porque consentes a injustiça e a fome?" 
(BRANDÃO, PASCOAES, 1984, p.51-54 passim). Bombardeado com essas acusações, que o perseguem mesmo durante a crucificação, Jesus, como aponta a didascália presente no fim do sexto quadro, "ouve tudo em silêncio, até que estende os braços, mostra as chagas das mãos e desata a chorar" (BRANDÃO, PASCOAES, 1984, p.100).

Como vemos, a peça de Brandão e Pascoaes retrata um Jesus fracassado e impotente, que não consegue mudar o mundo, nem consegue que a sua mensagem seja aceita. O seu retorno e o novo sofrimento na cruz resultam inúteis, pois os homens não querem a salvação que ele vem oferecer e acusam-no de querer destruir a vida: "Destruíste a vida! Quiseste destruir a vida!” (BRANDÃO, PASCOAES, 1984, p.100).

Já Fernando Pessoa revisitará Jesus Cristo e discorrerá sobre o cristismo tanto em prosa como em verso. Em dois poemas do heterônimo neoclássico, Ricardo Reis, datados de 9-10-1916, cujos primeiros versos são muito próximos, como também bastante parecidos os temas de que tratam, o poeta reconhece em Cristo apenas um Deus a mais, entre outros. No primeiro desses poemas, considera que o carpinteiro galileu é um "Deus triste, preciso talvez porque nenhum havia / Como tu, um a mais no Panteão e no culto". Se admite que não o odeia, reconhece porém odiar os idólatras exclusivos de Cristo, por quererem-no "acima dos outros teus iguais deuses". No segundo poema, reafirma que Cristo "Nem mais nem menos és, mas outro Deus"; e insiste "que os teus crentes te não ergam sobre / Outros, antigos Deuses que dataram / Por filhos de Saturno / De mais perto da origem igual das coisas" (PESSOA, 1986, p.271-273).

É, porém, no poema VIII de $O$ guardador de rebanhos que aparece uma imagem de Jesus bem diferente do modo como, desde a Geração de 70, este vinha sendo retratado. Publicado inicialmente no número 30 da revista Presença, de janeiro-fevereiro de 1931, viria a ser, com certeza, um dos poemas mais famosos do heterônimo Alberto Caeiro. Temos aqui não o Jesus crucificado e sofredor, que figurara em tantas obras anteriores a de Pessoa, não o Deus triste de Ricardo Reis, mas o Jesus "Tornado outra vez menino", que aparece no sonho do eu lírico do poema, para com ele brincar.

Eduardo Lourenço, que perscruta admiravelmente as relações entre Pessoa-Caeiro e os seus precursores do século XIX, mostra que o menino Jesus do poema VIII 
não desceu propriamente do céu nem mesmo do sonho a Alberto Caeiro, mas, mais culturalmente, do céu portátil, um pouco sulfúrico, de um outro Poeta [Guerra Junqueiro], que é então, não nos esqueçamos, não só o mais célebre dos poetas portugueses vivos, como uma espécie de herói cívico da ainda jovem República de que tinha sido o profeta veemente e mesmo cruel. (LOURENÇO, 1986, p.117)

Apesar das diferenças existentes entre a poética junqueiriana, plena de sarcasmos, e a de Pessoa-Caeiro, que Lourenço pontua, o crítico tem razão quando aproxima as duas obras. O prefácio da segunda edição de $A$ velhice do padre eterno revela um Jeová truculento e impotente, mascando as suas cóleras, gemendo os seus reumatismos, castrado e piolento, feroz, porco, cheirando a alho (JUNQUEIRO, s.d. p.24-28). Não muito diferente, pelo tom de deboche, é a descrição feita de Deus no poema VIII, de PessoaCaeiro: "um velho estúpido e doente, / Sempre a escarrar no chão / E a dizer indecências” (PESSOA, 1999, p.249-255). Esta imagem dessacralizada que se tem de Deus estende-se também ao restante do retrato da Sagrada Família. A esse respeito, Rebelo argumenta

Mas o esvaziamento do conteúdo dos grandes nominalismos efectua-se em Caeiro não só quanto à Natureza, mas também em relação a Deus, à divina Trindade, à Virgem Maria e a toda emblemática cristista. No poema VIII d'O guardador de rebanhos o despojamento dos atributos do nome vai mais longe, pois visa directamente o conteúdo ideológico do Cristianismo: o Espírito-Santo (sic), a Virgem-Maria (sic) e Jesus Cristo. O simbolismo cristão é aí submetido a um processo desrealizador, que reduz a iconografia do Paráclito à grotesca vulgaridade de uma cena doméstica que nada tem de edificante, caindo na blasfémia e atingindo até um tom que lembra o Junqueiro da Velhice do Padre Eterno, como já apontou Eduardo Lourenço. (REBELO, 1988, p.30)

Mais que isto. É o autor de Fernando rei da nossa Baviera, entretanto, que observa e acentua, parece que pela primeira vez, "a metamorfose final de imagem-mito "Jesus" no interior do círculo que de Antero chega até Pessoa”, ou seja, que vai da Geração de 70 até a Geração de Orpheu: 
Poucas metamorfoses são mais significativas da pulsão profunda do imaginário poético português dos fins do século XIX que aquela que nos conduz do pálido ou doce Jesus, de Antero, de Eça e ainda de Junqueiro, à eterna criança, duplo do Poeta, seu filho e seu pai ao mesmo tempo, em Alberto Caeiro. É a conversão da História (à maneira de Renan) em psicografia, em mitologia pessoal; da Transcendência, mesmo humanizada, em Imanência, tal como Caeiro-Pessoa a exprime nos versos famosos (...).

Esta transfiguração operada por Pessoa-Caeiro põe termo a um longo processo de desdivinização de Cristo e redivinização num sentido novo (religiosidade nova) de Jesus, oposto desde Antero (via Renan) ao Deus bíblico. (LOURENÇO, 1986, p.117)

De fato, o pálido ou doce Jesus de Antero, Eça e seus colegas de geração, aparece realmente muitas vezes rebaixado e desdivinizado. Lourenço também acrescenta que essa imagem do Jesus menino brincalhão e "Eterna Criança”, Pessoa deve a Junqueiro via Unamuno:

São vários os índices exteriores que nos provam o interesse de Pessoa pela obra de Unamuno, em geral, e pela obra que nos consagrou, em particular [Por tierras de Portugal y España]. É sabido que Guerra Junqueiro tem nela um papel capital. Com Oliveira Martins, está na origem de todas as imagens e mitos que Unamuno glosou acerca de Portugal. A que hoje nos interessa refere-se ao Cristo português, tal como Junqueiro o visionava (...). Eis o que nos conta D. Miguel de Unamuno: "El Cristo español - me decia una vez Guerra Junqueiro está sempre en su papel trágico: jamás baja de la cruz, donde, cadavérico, extiende sus brazos y alarga sus piernas cubiertas de sangre; el Cristo português anda por costas y prados y montañas, jugando con la gente de pueblo, se rie com ellos, merienda y cuando en cuando, para llenar su papel, se cuelga un rato de la cruz". (LOURENÇO, 1986, p.118, o trecho aparece em destaque está sublinhado pelo autor no original)

O autor de Fernando rei da nossa Baviera considera que o menino Jesus de Caeiro rediviniza o Cristo e põe fim a um processo de desdivinação que a sua imagem vinha sofrendo na literatura portuguesa produzida desde 
Antero. Obviamente, Antero de Quental é considerado um marco de sua geraçóo; afinal, foi figura cimeira e uma espécie de mentor intelectual do grupo a que pertenceu. Essa metamorfose, que para Eduardo Lourenço ocorreu na imagem de Jesus, prepara-nos para o novo percurso que a figura de Cristo alcançará na literatura portuguesa pós-Geração de 70. E sob essa expectativa que partiremos agora para a leitura de $O$ livro do menino-Deus (1945), de Aquilino Ribeiro.

Este livro de Aquilino apresenta-nos "um menino Jesus folclórico e um tudo-nada pagão", como o define Mário Martins (1969, p.231). Na primeira parte, intitulada "Legenda Bíblica”, é narrada basicamente a vida de Jesus da fecundação sobrenatural até a idade de doze anos, época em que, segundo a tradição biblica, teria ocorrido o seu confronto com os doutores do Templo.

Não é tão simples a classificação desse livro de Aquilino. No verbete dedicado a ele no Dicionário cronológico de autores portugueses, $O$ livro do menino-Deus é classificado como "história religiosa e etnografia" (LISBOA, 1994, v.III, p.323). De fato, o texto de Aquilino tem certa ambigüidade. Se, de um lado, o escritor segue as narrativas evangélicas, por outro, intercala muitas vezes à sua narrativa comentários sobre polêmicas de teólogos a respeito de alguns passos da vida de Jesus. Ou seja, podemos pensar que ele acaba por, indiretamente, questionar a verdade da história que está narrando. Em relação ao nascimento de Jesus, por exemplo, diz que

As vozes são discordes quanto à presença ou não presença da túnica placentária, secundina lhe chamavam S. Jerônimo e as nossas avós, que devia cingir o corpinho do Menino-Deus. Aquele venerável padre da Igreja, com Tertuliano e Abulense, mais recentemente Serry, são de parecer que o filho de Deus copiou em sua encarnação todos os achaques e vulgaridades dos filhos dos homens. Contra semelhante ousio insurgem-se porém a beata Maria de Agreda e Fr. José de Jesus Maria, que, tomando como premissa o modo miraculoso como o menino veio ao mundo, só vêem ordem lógica com preservá-lo da sórdida contingência puerperal. (RIBEIRO, 1983, p.27) 
Ainda falando desse nascimento, que, segundo a tradição bíblica, ocorreu "sem adjutório ou ministério de qualquer pessoa", Aquilino contesta esta tradição e, ironicamente, diz que se considera obrigado a censurar certos anacronismos, como o de "desmentir a boa da Santa Anastásia que se inculcou como parteira de Maria, não reparando os cândidos agiógrafos que caiam nos abismos do absurdo, ser antes de não ser” (RIBEIRO, 1983, p.26).

Certamente é por apontar essas que, segundo a ortodoxia, são vozes discordes, que o livro de Aquilino pode ser considerado bem mais que tudonada pagão. Ele próprio acrescenta a essas vozes a sua. Ao falar da ida ao Templo para a circuncisão do menino Jesus, depois de ter discorrido sobre a visita dos Reis Magos, comenta o fato de os pais de Jesus terem oferecido “em vez do anho da praxe um casalinho de rolas, óbolo dos necessitados". Indaga então: "Onde tinha passado o oiro, incenso e mirra que lhe ofereceram os Magos do Oriente?” (RIBEIRO, 1983, p.39). Com esses questionamentos, ao mostrar o que considera inconsistente nessas histórias da infância do menino Deus, fixadas pela tradição, Aquilino acaba também por colocar em xeque essa tradição.

Assim, seja mostrando as controvérsias dessas narrativas, seja revelando o absurdo e o anacronismo de certos padres e santos da Igreja em muitas de suas declarações a respeito da história bíblica, é esta história que acaba sendo questionada e revista por ele. Ou seja, alinha-se aos outros escritores portugueses que, antes dele, também questionaram a verdade dessa história.

Em relação às adversidades enfrentadas por Jesus, por exemplo, mostrao falível, um Jesus que não consegue converter a todos com a sua mensagem e se enfraquece diante dos poderosos. Ao considerar Jesus dessa maneira, Aquilino insere-se na tradição dos escritores portugueses que, desde a Geração de 70, vêm desdivinizando Cristo:

Ante o orgulho dos sábios e a força dos poderosos, a sua incomparável inteligência parecia amortecer-se; o seu poder sobrenatural eclipsava-se; o seu belo rasgo sofria quebra. Ele que ante os humildes, por toda a rude terra da Galileia, operava milagres sobre milagres, na presença dos doutores empavonados ou de criaturas capazes de exercerem a análise, quedava o simples e romântico filho de Maria de Nazaré. Quando Pilatos lhe objectou: 
“O que é a verdade?", baixou os olhos como se não achasse resposta à proposição do céptico na sua admirável ciência. (RIBEIRO, 1983, p.58)2

Todavia, apesar desse caráter de seu O livro do menino-Deus, a obra de Aquilino valoriza a Boa-nova anunciada por Jesus: "Numa palavra, vinha como mensageiro dum Deus universal, para quem todos os homens são irmãos, com iguais direitos à partilha dos seus dons. Este conceito, que forneceu a base da vida social moderna, cifrava toda a doutrina de Jesus”. Também não nega, de certa forma, a sua divindade, pois considera que foi "um Deus [que] veio morrer pelos homens na terrinha triste da Palestina” (RIBEIRO, 1983, p.57-59 passim).

Ou seja, com sua abordagem, Aquilino mantùm-se na mesma esfera daqueles que questionam, de um lado, sobretudo a postura dos teólogos e as muitas incoerências das narrativas evangélicas, mas que nutre, por outro lado, grande admiração pelo legado das idéias deixadas por Jesus, que é, aliás, a posição de muitos dos escritores vistos até aqui.

Seguindo os passos de Eça de Queirós e seus companheiros de geração, António Patrício, Teixeira de Pascoaes e Raul Brandão, Fernando Pessoa e Aquilino Ribeiro preparam o caminho que José Saramago trilhará, no fim do século XX, em seu $O$ Evangelho segundo Jesus Cristo ${ }^{3}$. A reflexão sobre a presença do elemento religioso como formador da identidade nacional tem estado presente, como vimos, na obra ficcional de importantes escritores portugueses dos séculos XIX e XX. Não apenas o clero e o seu comportamento têm sido colocados na berlinda, sobretudo nesses dois séculos que procuramos enfocar; a própria figura de Jesus passou a ser objeto de questionamento. Da dessacralização total, operada por Eça de Queirós em $A$ relíquia, que nega a divindade de Jesus, ao tratamento heterodoxo dado à legenda bíblica, nas obras dos autores comentadas neste ensaio, procura-

2 Aliás, a última parte dessa sua reflexão, Aquilino a deve, de fato, a Eça de Queirós, e não à tradição bíblica. O retrato que faz aqui do Jesus diante de Pilatos é o mesmo que encontramos em A relíquia. É no romance de Eça que Jesus baixa os olhose queda-se emudecido diante do questionamento do procurador romano. A intertextualidade que a obra de Aquilino estabelece nessa passagem é, sobretudo, com a leitura eciana.

3 A respeito do confronto entre o Evangelho de José Saramago e o sonho exegético do Teodorico de A relíquia, ver BUENO, 2000. 
mos delinear esse processo de "desdivinização de Cristo e redivinização num sentido novo".

\section{BIBLIOGRAFIA}

BRANDÃO, Raul e PASCOAES, Teixeira. Jesus Cristo em Lisboa. Lisboa: Vega, 1984.

BUENO, Aparecida de Fátima. Evangelhos finisseculares: os Cristos de Eça de Queirós e de José Saramago. Revista da Biblioteca Mário de Andrade, São Paulo, v. 58, p. 201-206, 2000.

JUNQUEIRO, Guerra. A velhice do padre eterno. Lisboa: Europa-América, s.d.

LISBOA, Eugénio (coord). Dicionário cronológico de autores portugueses (organizado pelo Instituto da Biblioteca Nacional e do Livro). v.3. Lisboa: Europa-América, 1994.

LOURENÇO, Eduardo. De Junqueiro a Pessoa. In: Fernando rei da nossa Baviera. Lisboa: Imprensa Nacional/Casa da Moeda, 1986. p.111-119.

MARTINS, Mário. Cristo na literatura portuguesa. In: COELHO, Jacinto do Prado (org). Dicionário de literatura. Rio de Janeiro: Companhia Brasileira de Publicações, 1969. p.230-231.

PATRÍCIO, António. Judas. In: Teatro completo. Lisboa: Assírio e Alvin, 1982. p.427-435.

PESSOA, Fernando. Fiç̧ões de interlúdio. São Paulo: Companhia das Letras, 1999.

PESSOA, Fernando. Obra poética. 3.ed. Rio de Janeiro: Nova Aguilar, 1986.

PIRES, António Machado. A ideia de decadência na Geração de 70. 2. ed. Lisboa: Vega, 1992.

REBELO, Luís de Sousa. Paganismo versus cristismo em Fernando Pessoa. Colóquio Letras, Lisboa, n.104-5, p. 26-33, jul.-out. 1988.

RIBEIRO, Aquilino. O livro do menino Deus. 2. ed. Lisboa: Bertrand, 1983.

SERRÃO, Joel. Dicionário de história de Portugal. Lisboa: Figueirinhas/Porto, 1971.

VASCONCELOS, José Manuel. Prefácio. In: BRANDÃO, Raul e PASCOAES, Teixeira. Jesus Cristo em Lisboa. Lisboa: Vega, 1984. p.9-16. 